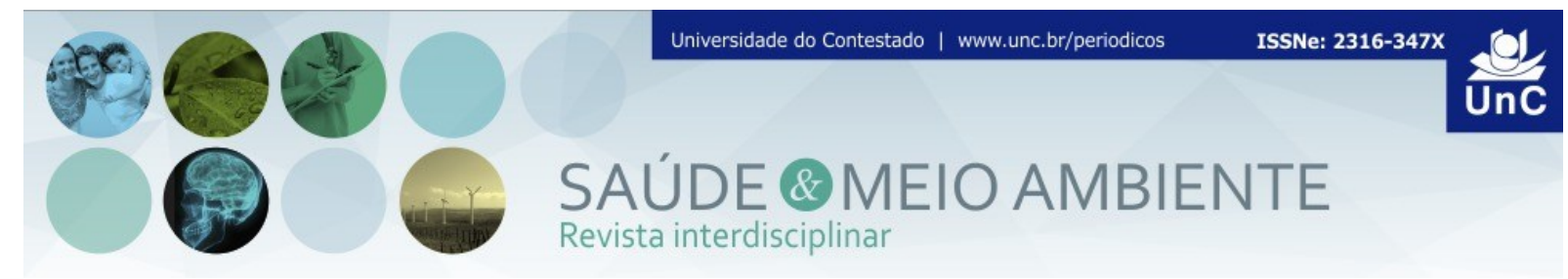

\title{
BENEFÍCIOS ECONÔMICOS E AMBIENTAIS DA SUSTENTABILIDADE ENERGÉTICA NA ILUMINAÇÃO DE AMBIENTES EXTERNOS ${ }^{1}$
}

\author{
Camila Falkoski \\ Mari Aurora Favero Reis ${ }^{3}$
}

\begin{abstract}
RESUMO: Com a crise energética estudos na melhoria de sistemas de energia são de extrema importância para a sustentabilidade energética e ambiental. Neste trabalho realizou-se estudos de viabilidade econômica, ambiental e tecnológica, os dados foram obtidos a partir de um projeto de eficiência elétrica para a iluminação ao ar livre em uma instituição de ensino superior do município de Concórdia (SC). Para este trabalho, que visa reduzir o consumo de eletricidade na iluminação ao ar livre da instituição, foram utilizadas planilhas programadas e pesquisa documental. Os resultados mostraram que, para melhorias na iluminação artificial em ambientes ao ar livre é necessária a substituição do sistema atual (lâmpadas de vapor de sódio e lâmpadas de mercúrio) para um sistema de lâmpada a LED, que promove a redução de impactos ambientais e proporciona a sustentabilidade energética. O estudo da mudança do sistema apresentou indicadores, viabilidade técnica, econômica e ambiental.
\end{abstract}

Palavras-chave: Iluminação artificial. Energia solar. Sustentabilidade.

\section{ECONOMIC AND ENVIRONMENTAL BENEFITS OF ENERGY SUSTAINABILITY IN LIGHTING OUTDOOR}

ABSTRACT: With the energy crisis studies in improving power systems are of utmost importance to the energy and environmental sustainability. This work was carried out feasibility studies, environmental and technological, data were obtained from an electrical efficiency of design for outdoor lighting in a higher education institution in the city of Concordia (SC). For this work, which aims to reduce electricity consumption in outdoor lighting of the institution, programmed spreadsheets and documentary research were used. The results showed that for improvements in artificial illumination in outdoor environments replacing the current system is required (sodium vapor lamps and mercury lamps) for a lamp system LED, which promotes the reduction of environmental impacts and provides energy sustainability. System change study presented indicators, technical feasibility, economic and environmental.

Keywords: Artificial lighting. Solar energy. Sustainability.

\footnotetext{
${ }^{1}$ Este artigo teve origem no projeto financiado pelo Art. 170.

${ }^{2}$ Curso de Engenharia Ambiental e Sanitária da Universidade do Contestado. Santa Catarina. Brasil. Foi Bolsista Art. 170. E-mail: camila.falkoski@hotmail.com

${ }^{3}$ Ms. Programa de Pós-Graduação em Ensino de Ciências e Matemática (ULBRA); atualmente é doutoranda do programa. E-mail: mari@unc.br
} 


\section{INTRODUÇÃO}

O ano de 2015 foi eleito como o Ano Internacional da Luz (AIL), pela $68^{\mathrm{a}}$ Assembleia Geral das Nações Unidas, em reconhecimento de sua importância para o desenvolvimento da Humanidade e em comemoração aos 110 anos da publicação do artigo de Albert Einstein sobre o efeito fotoelétrico (ATWATER, 2015). Esta iniciativa global vai destacar a importância da luz na vida dos seres humanos, bem como as tecnologias associadas à iluminação artificial e gestão energética.

Nos últimos anos o uso de energia elétrica na iluminação artificial vem passando por melhorias na prestação de serviço com a iluminação artificial, devido aos aumentos nas tarifas e as mudanças na gestão. Consequentemente, novas tecnologias surgem como alternativas e tendências na substituição das lâmpadas de vapor de sódio de alta pressão e lâmpadas de mercúrio (ASCURRA, 2013). Dos diferentes tipos de lâmpadas existentes no mercado para ambientes externos, além das variações no consumo, podemos destacar os impactos ambientais gerados pela radiação e pelas substâncias, tais como o mercúrio e o sódio presentes nas lâmpadas incandescentes e fluorescentes.

Uma alternativa é as vantagens das lâmpadas a LEDs, destaca-se a vida longa das lâmpadas, são compactas, baixo consumo de energia e baixa radiação de calor (WANG et al., 2012). Por conta disso, segundo os autores, espera-se que os LED venham a substituir de forma promissora as lâmpadas incandescentes e fluorescentes, consequentemente, passe a ser considerada o sistema de iluminação do futuro.

A estrutura da tecnologia a LED (Light Emitting Diode) é completamente diferente das lâmpadas convencionais, sendo baseada em uma tecnologia de semicondutor com funcionamento no efeito fotoelétrico. Os semicondutores comportam-se como isolantes até que uma fonte de energia externa seja capaz de "excitar" muitos de seus elétrons da banda de valência para a banda de condução, tornando-os portadores de carga em movimento (corrente); no caso de uma célula fotoelétrica, esta energia vem da luz (RICHARDS; ETKINA, 2013). Desse modo, o diodo que emite luz (fótons), e a corrente percorre uma única direção. Quando a eletricidade passa pelo diodo os átomos no material que contém o chip são 'excitados' e a energia contida ali é liberada, pelo efeito fotoelétrico, enquanto os átomos transmitem elétrons no material.

A tecnológica das luminárias LED (Light Emitting Diode), com baixo consumo de energia elétrica, tem proporcionando melhoria na eficiência dos sistemas de iluminação já existentes (ASCURRA, 2013). A recente década vivenciou melhorias significativas nos progressos de desenvolvimento de tecnológicos em semicondutores para diodos emissores de luz (LEDs), bem como a melhoria na eficiência (ALADOV et al., 2010). Paralelo a isso, segundo os autores, houve uma expansão na produção de LEDs devido à evolução científica e avanços tecnológicos em dispositivos comerciais, sendo que esta evolução superou as expectativas mais ousadas. 
No início do século XXI os especialistas esperavam que a eficácia luminosa de LED branco não iria exceder a $60-80 \mathrm{~lm} / \mathrm{W}$ até 2010 , porém em 2010 os LEDs comerciais apresentavam eficácia superior 110-120 Lm/W, tornando-se principal fontes de luz para uma ampla gama de aplicações, incluindo iluminação geral (ALADOV et al., 2010). Muitos foram os estímulos ao desenvolvimento e aplicações do LED por instituições públicas em países desenvolvidos, conforme os relatos dos autores citados, prêmios milionários foram oferecidos aos cientistas que desenvolvesse tecnologias de ponta para o domínio na eficácia das fontes de luz a LED.

Quanto à relevância ambiental, para que mudanças ocorram, novas ações fazem-se necessárias para reduzir os impactos causados ao meio ambiente. Além da redução no consumo de energia elétrica, a substituição da iluminação de vapor de sódio de alta pressão por iluminação com LED, pode ser aliada aos aspectos com a segurança e qualidade de vida. O uso das lâmpadas de vapor de sódio (ou de mercúrio) pode causar a contaminação dos recursos naturais, quando não destinadas corretamente, e das pessoas envolvidas na sua manipulação.

$\mathrm{Na}$ questão ambiental, além da redução no consumo e vantagens na substituição por tecnologias limpas (não contém mercúrio ou vapor de sódio), a iluminação a LED proporciona uma redução dos impactos da iluminação artificial sobre os ecossistemas (BARGHINI, 2008). Segundo o autor, a radiação ultravioleta, presente principalmente nas lâmpadas de mercúrio e vapor de sódio, representa um dos grandes atrativos aos insetos. Já a iluminação a LED pode ser melhor direcionada e contempla a radiação no espectro visível.

Devido aos custos na iluminação artificial e a influência dessa sobre o meio ambiente, é natural que em ambientes externos com baixa taxa de circulação humana, a iluminação artificial seja pouco desejável (BARGHINI, 2008). Entretanto, quando se trata de um ambiente público com atividades noturnas, com é o caso do local escolhido para este projeto, o uso de iluminação artificial é essencial. E, consequentemente, estudos em eficiência energética pode proporcionar melhorias na qualidade de vida dos ocupantes e melhor gestão nos recursos naturais e financeiros.

\section{METODOLOGIA}

\section{ÁREA DE ESTUDO}

O presente trabalho teve origem a partir de dados obtidos em projeto que faz parte do grupo de pesquisa Gestão Ambiental (GEMA) da Universidade do Contestado localizada no município de Concórdia - Santa Catarina, realizado por acadêmica do curso de Engenharia Sanitária e Ambiental. O estudo teve como objetivo avaliar a viabilidade econômica, ambiental e tecnológica para melhorias na 
eficiência energética e sustentabilidade na iluminação artificial nos ambientes externos do campus.

A instituição de ensino, a qual foi realizado o estudo, possui uma área construída de $13.746,61 \mathrm{~m}^{2}$, contempla iluminação artificial nas áreas dos estacionamentos e entorno das edificações e pavimentos. Foi avaliada a possibilidade de alteração do sistema atual de iluminação realizada por lâmpadas de pressão de sódio e lâmpadas de mercúrio por iluminarias a LED.

\section{PROCEDIMENTOS UTILIZADOS PARA COLETA DE DADOS}

A metodologia utilizada no levantamento de dados para o projeto foi quantitativa. Primeiramente buscou-se a quantificação dos postes de iluminação, número total de luminárias e demanda de consumo das mesmas. Também foi considerando a altura dos postes e o seu posicionamento no campus.

Para o estudo dos dados e avaliação técnica foram utilizadas planilhas eletrônicas programadas, disponibilizada pelo Programa de Eficiência Energética (CELESC) e os cálculos foram efetuados com base no consumo médio mensal de energia, a partir da fatura de eletricidade, e com dados obtidos na avaliação do sistema atual. Inicialmente foi avaliado para cada poste o consumo das lâmpadas, possíveis perdas, tempo de uso e possibilidades de melhorias através do programa de eficiência energética da Celesc.

\section{RESULTADOS E DISCUSSÃO}

$\mathrm{Na}$ quantificação dos postes com luminárias, a partir do levantamento realizado, verificou-se um total de 44 iluminarias externas, incluindo áreas como estacionamento, acessos aos ônibus e entorno dos prédios (tabela 01). Na avaliação não foram considerados os acessos com coberturas (toldos). Nestas, que consideramos como áreas cobertas (internas), possuem lâmpadas de mercúrio, as mesmas utilizadas no interior das edificações da instituição.

Tabela 1 - Quantificação das lâmpadas.

\begin{tabular}{lcc}
\hline Modelo Lâmpada & Quantidade & Watts \\
\hline Vapor de Mercúrio & 20 & 250 \\
\hline Vapor de Sódio & 24 & 400 \\
\hline
\end{tabular}

Fonte: Autor, 2014 
Além das lâmpadas, também foi considerado o consumo com os reatores e perdas no sistema de transmissão (cabeamento e adaptadores), pois o sistema é antigo com muitas perdas energéticas. Portanto, a partir do estudo observamos que o sistema atual tem alto consumo e baixa eficiência energética (em Lm/W), demonstrando necessidades emergentes em investimentos na melhoria do sistema de iluminação artificial nos ambientes externos da instituição.

Por conta disso, realizou-se um estudo de tecnologias modernas para iluminação de modo que reduzisse a demanda energética. Nesta pesquisa verificouse a possibilidade de substituir as lâmpadas e seus respectivos reatores por iluminarias de LED, com mesma intensidade luminosa.

Para a avaliação com a viabilidade econômica foi utilizado a planilha do Programa de eficiência energética (PeeCelesc 2014), que demonstrou uma economia anual de energia a substituição iluminação atual, por lâmpadas de Led, onde a mesma necessita a implantação de 20 lâmpadas de 250watts, em substituição das 24 lâmpadas de 400 watts e, os 44 reatores de 70 watts (numa potência instalada de 11,28kwatts para lâmpadas com 400watts e 6,40kwatts para lâmpadas de 250watts), o sistema atual consome 51,63MWh-ano, e o sistema proposto 4,4kwatts de potência instalada, um total de 12,85MWh-ano. (Quadro I).

Há aspectos não mensuráveis neste projeto que apresentam avanços quanto à infraestrutura e a manutenção. A substituição da iluminação externa demanda, consequentemente, no aumento da vida útil de cada lâmpada, diminuindo a necessidade de substituição de lâmpadas e reatores. A redução nas intervenções em manutenção do sistema de iluminação externa representa um ganho quantitativo e qualitativo, uma vez que ocorrem frequentemente falhas e necessidade de manutenção e reposições. O tempo destinado a manutenção poderia, por exemplo, ser utilizados em manutenção preventiva de todo o sistema energético, o que representa economia energética. A eliminação de eventuais perdas energéticas em outras áreas do sistema poderá ser investigada pela manutenção, sendo que a redução no fluxo de tensão também aumenta a segurança efetiva do sistema atual, reduzindo os riscos de sobreaquecimento no sistema.

Para os cálculos da eficiência energética na substituição das lâmpadas tradicionais, foi considerado os 22 dias durante o mês e foi necessário realizar um levantamento de valores com a lluminação pública ZL3300 - 100W a (LED), conforme a (Tabela 2).

Tabela 2 - Custo do Material para a lluminação a LED

\begin{tabular}{|c|c|c|c|c|}
\hline Material & Vida útil & Quantidade & Preço unitário & Custo total \\
\hline $\begin{array}{l}\text { Iluminação a } \\
\text { LED (100W) }\end{array}$ & $50.000 \mathrm{hrs}$ & 44 & $1.017,00$ & $\mathrm{R} \$ 44.748,00$ \\
\hline
\end{tabular}

Fonte: PeeCelesc, 2014. 
A viabilidade econômica apresenta retorno significativo ao investimento, em referência aos valores energéticos praticados atualmente. $\mathrm{O}$ histórico energético tem demonstrado tendência de aumento nas tarifas de energia elétrica com o passar do tempo e, portanto, a estimativa de retorno ao investimento é conservadora positiva, devido às tendências de aumento da energia no futuro. Ainda, a modernização do sistema apresenta garantia dos equipamentos instalados, por conta disso a instituição não investirá recursos nos próximos anos no sistema de iluminação externa.

Quanto aos ganhos ambientais, hoje são produzidos uma quantidade de resíduos originados da substituição dessas lâmpadas. Estes resíduos deveriam ser destinados a reciclagem, evitando as possíveis contaminações dos recursos ambientais e pessoas que manipulam de forma inadequada esses resíduos. Em nossa região, esta realidade ainda é incomum.

\section{CONSIDERAÇÕES FINAIS}

A iluminação artificial representa uma parcela considerável da energia elétrica consumida atualmente, como demonstrou no estudo com a instituição pesquisada. $O$ desenvolvimento de sistemas mais eficientes de iluminação, que faça uso dos recursos energéticos de forma sustentável é de extrema importância.

Com a execução do projeto obteve-se bons resultados de viabilidade técnica e econômica. A partir da planilha do programa de eficiência energética da Celesc constatou-se a substituição das lâmpadas de vapor de sódio e de mercúrio por iluminarias de LED poderá proporcionar uma redução de $75,11 \%$ no consumo de energia. Portanto, com uma redução anual de $R \$ 14.540,80$ na fatura de energia é possível em aproximadamente quatro anos recuperar os investimentos iniciais de implantação do novo sistema.

Quanto aos ganhos ambientais, os resultados são incalculáveis. Além da reduções dos resíduos contaminantes, pesquisas demonstraram um ganho na conservação dos ecossistemas e preservação da biodiversidade (BARGHINI, 2008). Nessa perspectiva a iluminação artificial nos ambientes externos, através da utilização de lâmpadas de Led se faz necessária, na qual minimiza os impactos ambientais e proporciona a sustentabilidade energética. 


\section{REFERÊNCIAS}

ALADOV, A. $V$ et al. On modern high-power leds and their lighting application . v. 18, n. 3, p. 16-29, 2010.

ASCURRA, R. E. Eficiência elétrica em iluminação pública utilizando tecnologia led : um estudo de caso. Dissertação apresentada junto ao Programa de PósGraduação em Engenharia de Edificações e Ambiental da Universidade Federal de Mato Grosso,2013.

ATWATER, H. A. 2015: The International Year of Light. ACS Photonics, v. 2, n. 1, p. 1-1, 2015.

BARGHINI, A. Influência da lluminação Artificial sobre a Vida Silvestre: técnicas para minimizar os impactos, com especial enfoque sobre os insetos. Revista Brasileira de Ciências Ambientais, p. 229, 2008.

RICHARDS, A. J.; ETKINA, E. Kinaesthetic learning activities and learning about solar cells. Physics Education, v. 48, n. 5, p. 578, 2013.

WANG, J. Y. et al. Experimental study on visible light communication based on LED. Journal of China Universities of Posts and Telecommunications, v. 19, $n$.

October, p. 197-200, 2012. 


\section{QUADRO I - PLANILHA UTILIZADA NO ESTUDO DE VIABILIDADE ECONÔMICA}

\begin{tabular}{|c|c|c|c|c|c|c|}
\hline \multicolumn{4}{|c|}{ ILUMINAÇÃO SISTEMA ATUAL } & TOTAL & ilumin 1 & ilumin 2 \\
\hline \multicolumn{4}{|c|}{ Tipo de equipamento / tecnologia } & TOTAL & ilumin 1 & ilumin 2 \\
\hline \multirow{2}{*}{ Lâmpadas } & Potência & W & $p / a_{i}$ & 650,00 & 400 & 250 \\
\hline & Quantidade & & qla & 44 & 24 & 20 \\
\hline \multirow{2}{*}{ Reatores } & Potência & W & pra $_{i}$ & 140,00 & 70 & 70 \\
\hline & Quantidade & & qra $_{i}$ & 44 & 24 & 20 \\
\hline \multicolumn{2}{|c|}{ Potência instalada } & $\mathrm{kW}$ & $P a_{i}$ & 17,68 & 11,28 & 6,40 \\
\hline \multicolumn{2}{|c|}{ Tempo de utilização do sistema, em um dia } & h/dia & & & 8,00 & 8,00 \\
\hline \multicolumn{2}{|c|}{ Dias de utilização do sistema, em um ano } & dia/ano & & & 365,00 & 365,00 \\
\hline \multicolumn{2}{|c|}{ Funcionamento } & h/ano & $h a_{i}$ & & $2.920,00$ & $2.920,00$ \\
\hline \multicolumn{2}{|c|}{ Meses no ano, de utilização do Sistema no horário de Ponta } & meses & NM & 12 & 12 & 12 \\
\hline \multicolumn{2}{|c|}{ Dias úteis no mês, de utilização do Sistema no horário de Ponta } & dias & $N D$ & 22 & 22 & 22 \\
\hline \multicolumn{2}{|c|}{ Horas por dia, de utilização do Sistema no horário de Ponta } & horas & NUP & 3 & 3 & 3 \\
\hline \multicolumn{2}{|c|}{ Potência média na ponta } & $\mathrm{kW}$ & $d a_{i}$ & 17,68 & 11,28 & 6,40 \\
\hline \multicolumn{2}{|c|}{ Fator de coincidência na ponta } & & $F C P a_{i}$ & & 1,00 & 1,00 \\
\hline \multicolumn{2}{|c|}{ Energia consumida } & MWh/ano & $E a_{i}$ & 51,63 & 32,94 & 18,69 \\
\hline \multicolumn{2}{|c|}{ Demanda média na ponta } & $\mathrm{kW}$ & $D a_{i}$ & 17,68 & 11,28 & 6,40 \\
\hline \multicolumn{4}{|c|}{ SISTEMA PROPOSTO } & & ilumin 1 & ilumin 2 \\
\hline \multicolumn{7}{|c|}{ Tipo de equipamento / tecnologia } \\
\hline \multirow{2}{*}{ Lâmpadas } & Potência & W & $p / p_{i}$ & 200,00 & 100 & 100 \\
\hline & Quantidade & & $q / p_{i}$ & 44 & 24 & 20 \\
\hline \multirow{2}{*}{ Reatores } & Potência & W & $\operatorname{prp}_{i}$ & 0,00 & & \\
\hline & Quantidade & & $\operatorname{qrp}_{i}$ & 0 & & \\
\hline
\end{tabular}

Saúde Meio Ambient. v. 5, n. 1, p. 117-125, jan./jun. 2016 


\begin{tabular}{|c|c|c|c|c|c|}
\hline Potência instalada & $\mathrm{kW}$ & $P p_{i}$ & 4,40 & 2,40 & 2,00 \\
\hline Tempo de utilização do sistema, em um dia & $\mathrm{h} / \mathrm{dia}$ & & & 8,00 & 8,00 \\
\hline Funcionamento & h/ano & $h p_{i}$ & & $2.920,00$ & $2.920,00$ \\
\hline Meses no ano, de utilização do Sistema no horário de Ponta & meses & NM & 12 & 12 & 12 \\
\hline Dias úteis no mês, de utilização do Sistema no horário de Ponta & dias & ND & 22 & 22 & 22 \\
\hline Fator de coincidência na ponta & & $F C P p_{i}$ & & 1,00 & 1,00 \\
\hline Energia consumida & MWh/ano & $E p_{i}$ & 12,85 & 7,01 & 5,84 \\
\hline Demanda média na ponta & $\mathrm{kW}$ & $D p_{i}$ & 4,40 & 2,40 & 2,00 \\
\hline RESULTADOS ESPERADOS & & & TOTAL & ilumin 1 & ilumin 2 \\
\hline Custo da energia evitada (CEE) = & $\%$ & $E E_{i} \%$ & $75,11 \%$ & $78,72 \%$ & $68,75 \%$ \\
\hline Benefício anualizado iluminação & $\mathbf{R} \$$ & $B_{I L U M}$ & $14.540,80$ & $9.723,06$ & $4.817,73$ \\
\hline
\end{tabular}

Fonte: Planilha fornecida pelo PeeCelesc, 2014.

Artigo recebido em: 28/04/2015

Artigo aprovado em: 16/06/2016 